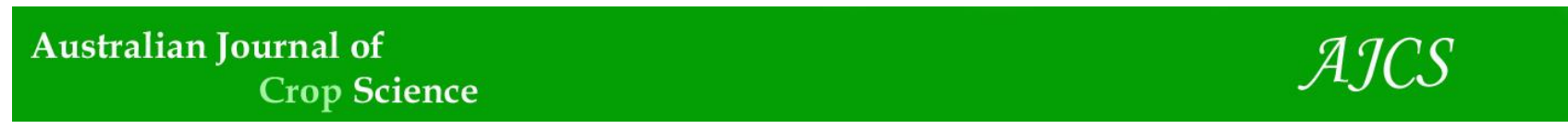

AJCS 10(6):765-770 (2016)

ISSN:1835-2707

DOI: 10.21475/ajcs.2016.10.06.p6678

\title{
Efficiency and losses in mechanical harvesting of soybeans due to the plots format
}

\author{
Carla Segatto Strini Paixão ${ }^{1 *}$, Rouverson Pereira da Silva ${ }^{1}$, Murilo Aparecido Voltarelli², Marcelo \\ Tufaile Cassia $^{1}$, Tiago de Oliveira Tavares ${ }^{1}$
}

\author{
1UNESP - Univ Estadual Paulista, Campus de Jaboticabal, SP, Department of Agricultural Engineering, Via de \\ Acesso Prof. Paulo Donato Castellane, s/n, 14884-900, São Paulo, Brazil \\ 2Universidade Federal de Viçosa, Viçosa, MG, Department Agricultural Engineering, Avenida Peter Henry \\ Rolfs, s/n - 36570-900, Minas Gerais, Brasil
}

*Corresponding author: ca_paixao@live.com

\begin{abstract}
Information about the capacity of the operation, harvest efficiency and performance of the harvester are of great importance in the management of agricultural mechanized systems, assisting in the decisions to be taken by the management aimed at its optimization. Mechanized harvesting was carried out at the farm located in Uberaba, Minas Gerais, in which eight repetitions for each evaluated plot format (irregular rectangular and trapezoidal) were performed. The activities of the harvester (harvest, unloading grain, harvest problems and climate pauses were monitored up. In determining losses circular frames were used with hoops made of $0.33 \mathrm{~m}^{2}$, then were released soon after the harvester's platform passed, in pre-determined points. Two frames were located outside of the harvest machine (left and right) and a third was located between the rear wheelsets (centre). The total losses refer to the sum of losses on the platform and of the internal mechanisms. The rectangular plot allowed a better use of available time for harvest, and presented greater efficiency of time compared to the other plots. By contrast the irregular plot, showed reduction in relation the grain discharge logistics, when comparing with the others plots Among the losses were no differences in the formats of plots evaluated and to the sampling site, with samples taken at the centre of the harvest machine presenting less variability.
\end{abstract}

Keywords: Glycine max (L.) Merrill; harvest efficiency; statistical process control.

Abreviações: UCL_upper control limit; LCL_lower control limit; $\bar{X} \_$individuals average; $\overline{\mathrm{M}} \overline{\mathrm{R}} \_$moving range average; $\sigma \_s t a n d a r d$ deviation; CV_variation coefficient; Ks_skewness; Kc_kurtosis; Coefficient AD_value of Anderson-Darling normality test; $p$-Value _probability distribution value; N_normal distribution $-\mathrm{p}>0.05$; A_no normal distribution $-\mathrm{p}<0.05$.

\section{Introduction}

Soybean (Glycine max (L.) Merrill) has great economic importance worldwide because of the extensive use of soybean for multiple purposes and the exceptional adaptability of soybean to a diversity of regions (Bianco et al., 2012). During the production process, numerous factors can affect soybean quality, from the installation of a production field until the storage of harvested soybean; however, the harvesting step is considered to be the most critical and important phase of the entire process (Carvalho and Novembre, 2012). Field efficiency is an important criterion to check the field capacity and to make important decisions about the management of the machines, especially at harvest (Grisso et al., 2004). According to ASAE standard D497.6 (2009) this efficiency is related to the unused total working width of the machine, with the operator's habits, time and maneuvering characteristics of the area and shape of the blocks. According to Hunt et al. (2001), time efficiency is the result of the relation between the time that the machine has worked effectively in field operation and the time it used to perform the operation. With increased field efficiency the production cost of the mechanical harvesting system will decrease and the net income will raise (Santos et al., 2014). Despite the high technology available to soybean harvest in Brazil, losses may occur during this process, reducing productivity and profits of producers (Holtz et. al, 2013).The high variability found in assessments of losses is one factor that deserves further investigation, since the variability affects the quality of the harvesting operation (Loureiro et al., 2014). With trying to minimize losses in the mechanized harvesting, the use of statistical control process tools is essential for monitoring the process, detection the actions of special causes and, finally, to create an improvement plan to eliminate extrinsic influence of the process actions, which, consequently, will increase the quality of operations by reducing the variability due to the same (Voltarelli et al., 2013). Quality control is perfectly adaptable to the agricultural production system; however, the use of statistical process control (SPC) to evaluate and/or monitor the quality of mechanised agricultural operations is still in its incipient stage in Brazil. Nevertheless, a number studies have applied SPC tools to the mechanized harvest of beans (Silva et al., 2013), coffee (Custodio et al., 2012; Cassia et al., 2013), soybean (Chioderoli et al., 2012), and sugarcane (Noronha et al., 2011).

Considering these facts, assuming that the performance of mechanized harvesting of soybeans operation can be influenced by the format of the plots where the culture was established, the aim of this study was to evaluate the efficiency and losses in mechanical harvesting of soybeans in different formats plots, using statistical process control tools. 


\section{Results}

\section{Efficiency time}

The control chart for the harvester operational efficiency as a function of plot shape (Fig 1) reveals a high variability in the harvesting process for the three plots evaluated, reflected by the high variability in the control limits. The amplitude between the limits for the rectangular plot was relatively low compared to the other plots, which represents the lower variability in the operation of this plot.

The plot of format rectangular was characterised by a longer mean time of effective harvester operation (greater than $80 \%$ of the total), followed by the irregular plot shape (approximately 70\%) and then the trapezoidal shape, which was associated with the poorest harvest conditions (less than $60 \%$ of time in effective operation). Finally, there were two occurrences during the harvest period in plot rectangular associated with a lower range between the control limits because of the lower variability in the process, which contributed to the lower instability of the harvester operation. In the Fig 2 presents the proportion of time spent on each harvester function in each plot from the onset of the harvest operation at 10-minute intervals. In the graph, the radial lines represent the 10-minute intervals and tangents represent the scale, in percentage. Comparing the three plots, the irregular plot (Fig 2a) required a longer bean unloading time for the harvester because the plot shape did not favour the logistics of bean unloading and transport, with $50 \%$ of the time required for this activity alone. There was no considerable difference between the other two plot shapes, but the trapezoidal plot (Fig 2b) was characterised by a better performance for bean unloading because the plot shape was favourable for unloading, thus accelerating the harvesting process.

There was a lower overall variability for harvester problems because of the lower frequency of occurrence of these situations, mainly related to the machine performance and the crop to be harvested. The irregular plot shape required longer time expenditure for dealing with unforeseen problems because it had rained at the site, resulting in unfavourable conditions that were associated with regular jams when the operator increased the harvester speed.

There was a high variability for the weather-related pauses, regardless of the plot shape, because the weather was an uncontrolled variable in this study. There were a number of pauses in all of the plots, which confirms the instability of the harvesting process. Notably, the trapezoidal plot was characterised by the largest number of weather-related pauses, and it was necessary to end the harvesting operation one day and return on another. Thus, the rectangular plot (Fig 2c) required the longest total operation time for the harvest. We attribute this longer duration of time to the fact that the crop was wet, and the conditions were poor for harvesting.

\section{Individual control charts for losses}

There was a difference amongst soybean losses for the plot shapes evaluated (Fig 3). The irregular plot shape was characterised by a higher variability in soybean losses (Fig 3a, 3b). Except for the losses collected between the tire wheelsets (centre), there was a higher mean loss and a higher variability for the trapezoidal plot shape (Fig 3c).

For total losses the plot of shape irregular presented more values and variability when compared to other plots (irregular and rectangular) (Fig 4). It is noted the presence of one point out of control in this spot, this occurrence is mainly due to the difficulty of maintaining the platform in the ideal position, thus hindering the harvest.

\section{Descriptive statistics for losses}

Based on the control charts for the bean losses for each plot (Fig 5), there were a number of outliers, except for the bean losses collected between the tire wheelsets (centre). These outliers were included in the statistical analyses because they are the result of the harvesting process and their further analysis can help to identify the occurrences of non-random causes of bean losses. The mean total loss was high for the three plots evaluated, exceeding the $1 \%$ tolerance level for all plots. Based on the analysis of control charts for individual harvester functions and the variation in the soybean harvesting process, the mean and median soybean loss values differed greatly, reflecting the asymmetric distribution, as confirmed by the test of normality (Table 3 ). The coefficients of variation for the losses were very high for all of the plots evaluated, regardless of where the losses were characterised (sides or centre), indicating that the results recorded at the sample locations varied greatly from the mean.

The high positive kurtosis coefficients (Kc) (except for the soybean losses collected in the centre, between the tire wheelsets) indicate that there is a high concentration of values close to the mean, whereas the slightly positive asymmetry coefficients demonstrate a trend of increasing losses. The high coefficient of variation is attributed to the maximum values being equal or very close to the amplitude, demonstrating that there are certain times associated with very low losses and other times associated with extremely high losses.

\section{Discussion}

\section{Efficiency time}

The efficiency of a harvest system basically depends on the environment where it is working, and the main factors to consider are the weather, the terrain, the plant species, and the infrastructure. The operational planning the activities is to establish alternatives that provide compliance with production targets that are determined by the overall planning, through knowledge of efficiency and operational performance of machinery and equipment used in the harvest (Linhares et al., 2012). In studies by Molin et al. (2010) observed that field efficiency indicates how efficient the system with regard to the influence of the operation time and unloading times. The managerial efficiency indicates the influence of downtime on the operation. The overall efficiency indicates how much of the total time available field is actually being used for harvest. According to Araldi et al. (2013), the harvert problems and bean unloading required, on average, 11.1 and $10.8 \%$ of the total operation time during soybean harvest, respectively. By eliminating the time lost to bean unloading and to unforeseen problems, the field efficiency can be improved by approximately $13.4 \%$.

\section{Descriptive statistics parameters}

The analysis of datasets, especially variability, can be used to monitor data dispersion over time and detect possible flaws occurring during the operation (Mudholkar and Natarajan, 
Table 1. Characteristics of the plots evaluated and their respective areas.

\begin{tabular}{lccc}
\hline Shape Plot & Irregular & Trapezoidal & Rectangular \\
\hline Area & $5.14 \mathrm{ha}$ & $4.82 \mathrm{ha}$ & $6.97 \mathrm{ha}$ \\
Length & $400 \mathrm{~m}$ & $617 \mathrm{~m}$ & $480 \mathrm{~m}$ \\
Width & $107 \mathrm{~m}$ & $97 \mathrm{~m}$ & $153 \mathrm{~m}$ \\
\hline
\end{tabular}

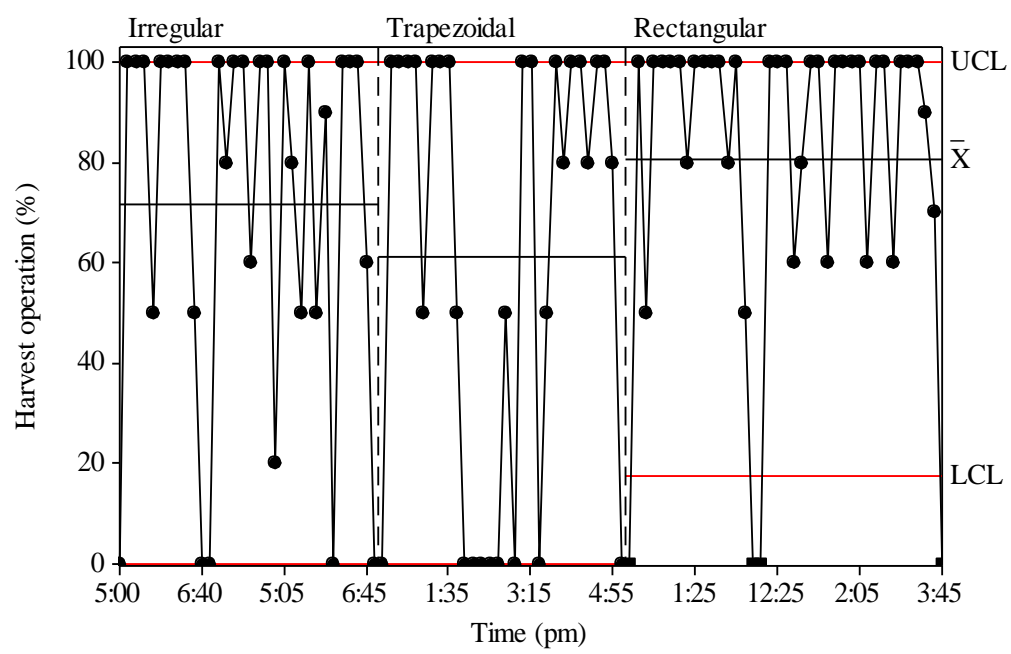

Fig 1. Control chart to the efficiency of harvesting operations throughout the experiment for the three plots.

Table 2. Soybean harvester of activities throughout the harvesting operation, monitored during the experiment.

\begin{tabular}{ll}
\hline Observations & Description \\
\hline Harvest operation & $\begin{array}{l}\text { Time during which the machine performed the intended mechanised harvest } \\
\text { operation, including manoeuvring times. }\end{array}$ \\
Bean unloading & $\begin{array}{l}\text { Time required for the machine to move to the unloading points, unload the } \\
\text { beans, and return to harvest activity. }\end{array}$ \\
\hline Harvester problems & Time required to resolve unforeseen problems, such as repairs and/ or jams. \\
\hline Climatic pauses & $\begin{array}{l}\text { Time devoted to pauses caused by adverse weather conditions, before returning } \\
\text { to the harvesting operation in the plot. }\end{array}$ \\
\hline
\end{tabular}

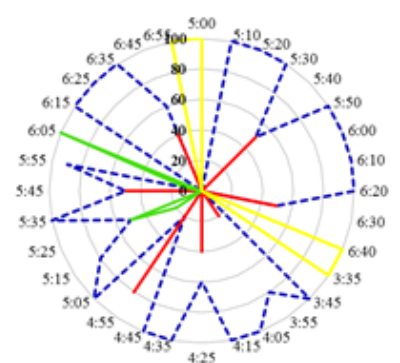

(a)

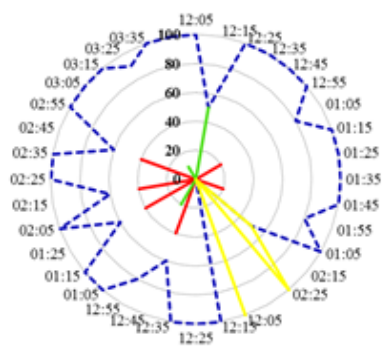

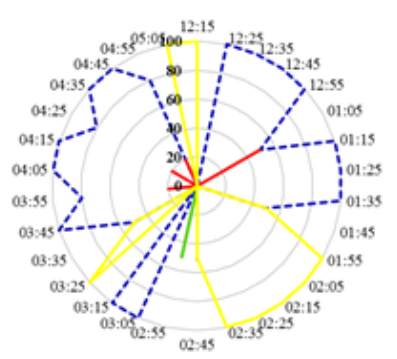

(b)

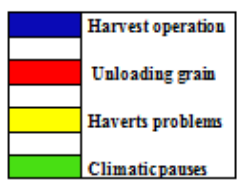

Fig 2. Radar graph to show, as a percentage, the monitoring of harvesting operation, unloading grain, harvest problem and climatic pauses in the three plots evaluated a) irregular plot; b) trapezoidal plot; c) rectangular plot. 
Table 3. Statistical analyses for the soybean losses recorded on the right side of the harvester; in the centre of the harvester; on the left side of the harvester; and for the total losses.

\begin{tabular}{llllllllllc}
\hline Position & Average & Median & $\sigma$ & Range & CV & Ks & Kc & AD & p-Value & Distribuition \\
\hline Right & 1.49 & 1.06 & 1.28 & 5.90 & 85.78 & 1.95 & 5.03 & 1.255 & $<0.005$ & A \\
Centre & 1.73 & 1.80 & 0.94 & 3.72 & 54.44 & 0.24 & -0.55 & 0.218 & 0.82 & N \\
Left & 1.65 & 1.20 & 2.24 & 11.42 & 135.28 & 0.18 & 19.01 & 4.034 & $<0.005$ & A \\
Total & 4.88 & 4.54 & 2.85 & 14.19 & 58.39 & 2.41 & 8.48 & 0.200 & $<0.005$ & A \\
\hline
\end{tabular}

$\sigma$ - standard deviation; CV - variation coefficient ; Ks- Skewness coefficient; Kc - Kurtosis coefficient; AD - value of Anderson-Darling normality test; p-Value probability distribution value. (N: normal distribution $-\mathrm{p}>0.05$; A: no normal distribution $-\mathrm{p}<0.05$ ).

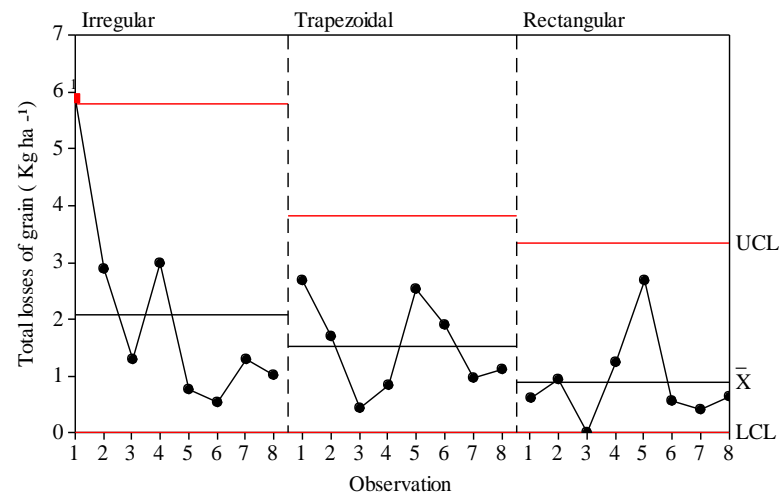

A

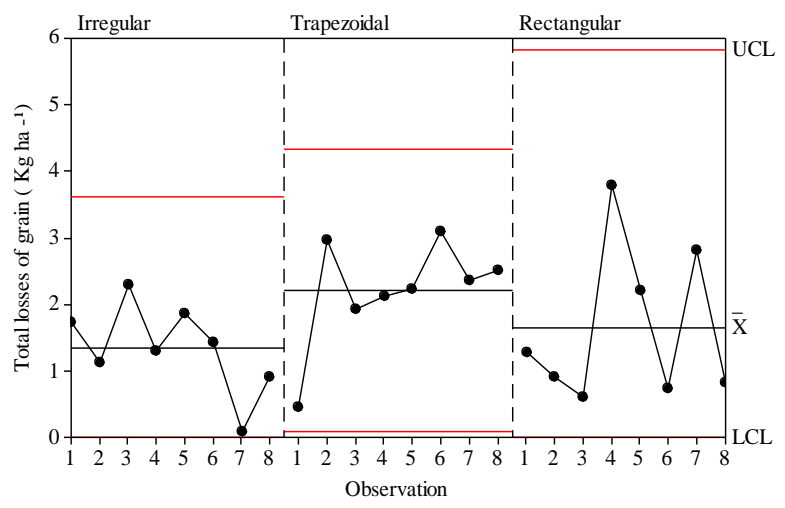

B

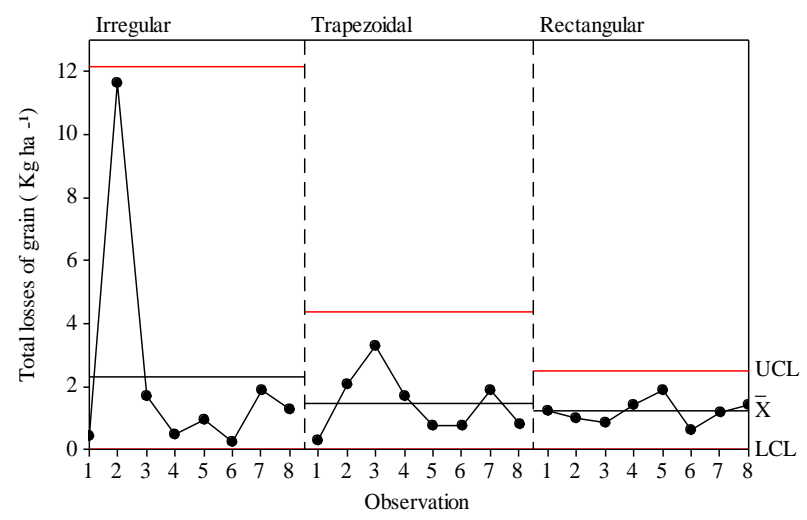

$\mathrm{C}$

Fig 3. Control charts for the soybean losses from the mechanised soybean harvest for the irregular, rectangular, and trapezoidal plot shapes recorded a) on the right side of the harvester; b) in the centre of the harvester; c) on the left side of the harvester.
2002; Kim and White, 2004). The study of descriptive statistics is also essential for assessing the general behaviour of datasets (Léon et al., 2005). Further information on the behaviour of datasets and their interpretation and on the analysis of normal distributions was explained by Bai (2003). Bai and $\mathrm{Ng}$ (2005) reported an association between the mean and standard deviation that can be used to predict data behaviour, with data monitoring over time, in which they somewhat affect the higher or lower variation of the dataset. A normal distribution of the data is a pre-requisite of statistical process control and the calculation of process capability indices to more accurately estimate process capability over time (Montgomery, 2004). Bakir (2012) reported that a normal distribution is desirable for performing process capability analysis and for such analysis to be representative. Further information on studies of normality associated with the use of statistical process control can be found in Chakraborti (2006) and Zhou and Tsung (2010).

\section{Harvest losses}

According to Carvalho Filho et al. (2005) the crop losses are influenced by inherent culture factors as factors related to the harvester. The choice to the cultivars suitable for the region, sowing time, cultural practices and minimizing crop losses is among the main factors affecting productivity, it is necessary to know cultural practices consistent with economic production. Costa et al. (2002) confirmed that the axial harvesters have greater harvesting capacity and offer reduction of mechanical damage to the seeds, while still presenting an acquisition cost considered high for Brazilian producers.

\section{Individuals control charts}

A normal distribution is essential for determining the process capability of production, conforming items. Otherwise, the process can be underestimated and will not reflect the situation accurately, requiring data transformation to perform the analysis. Further information on the effects of nonnormality and process stability on the subsequent analysis of process capability can be found in Somerville and Montgomery (1996) and Abbasi (2009). Toledo (2008) studied the quality of mechanised planting operation in the region of Jaboticabal, São Paulo, Brazil using control charts and found some of them to be stable or to indicate a predictable process suitable for the analysis of process capability, similar to this study, for which the process capability could be estimated. According to Shinde and Katikar (2012), the use of statistical process controls for 


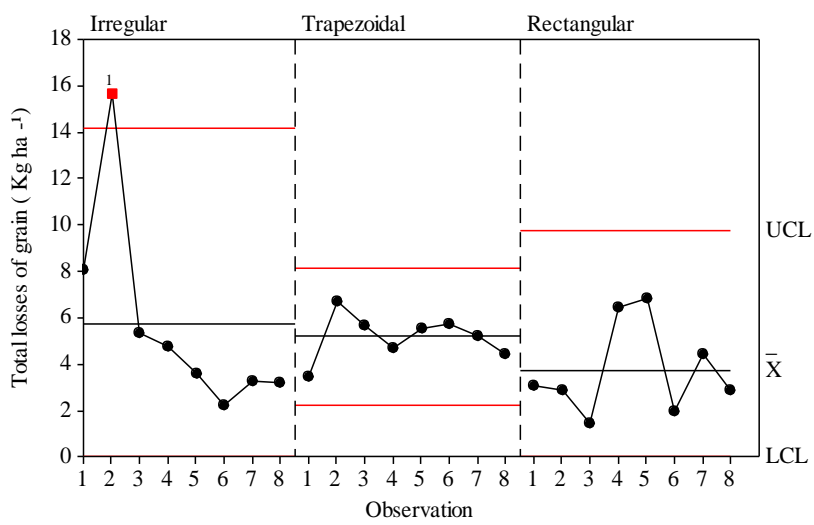

Fig 4. Control charts for the soybean losses from the mechanised soybean harvest for the irregular, trapezoidal and rectangular plot shapes recorded for the total losses.

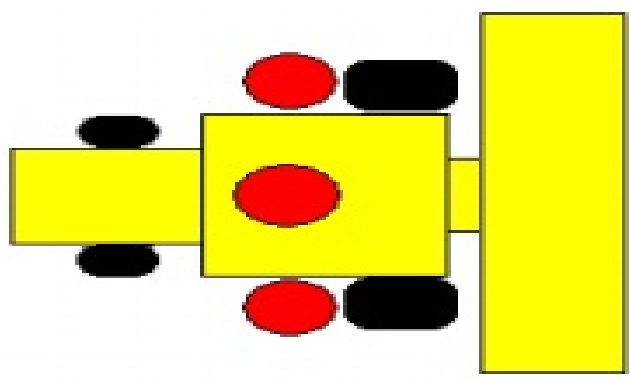

Fig 5. Position of screen (in red) for evaluation of losses.

the monitoring and consequent development of improvement plans to increase the quality of produced items is essential for reducing production costs by decreasing the production of defective items. In this study, all evaluated quality indicators were found to be related to the production costs of mechanised sugarcane planting, and if this operation is well controlled and monitored over time, its financial returns can be increased.

\section{Materials and Methods}

\section{Experimental conditions}

The experiment was performed in March 2013, within an area of the Nossa Senhora Aparecida farm, in Uberaba, MG, Brazil, located at the coordinates, 19\%4 $44^{\prime} 54^{\prime \prime S}$ latitude and $47^{\circ} 55^{\prime} 55^{\prime \prime} \mathrm{W}$ longitude, with a mean altitude of $801 \mathrm{~m}$ and a Köeppen climatic classification of Aw. The soil of the experimental site is classified as a typical, eutrophic red latosol with a clayey texture.

\section{Experimental design and plant materials}

Three shapes of plots with similar areas were evaluated (Table 1). The soybean crop was sown with the super-young variety AS7307RR from the Agroeste Company. The rows were spaced $0.50 \mathrm{~m}$ apart, with 17 to 18 plants $\mathrm{m}^{-1}$, for a mean total population of 350.000 plants $\mathrm{ha}^{-1}$. A Massey Ferguson harvester (model FW 5650 Advanced, year 2010, with approximately 700 hours of work) was used for the mechanised soybean harvest. The harvester has an AGCO Sisu Power six-cylinder motor, with a rated power output of $130 \mathrm{~kW}(175 \mathrm{hp})$ at $2.570 \mathrm{rpm}$. The harvester is equipped with $5.50 \mathrm{~m}$ wide cutting platform and a tangential trail system, a straw walker for separation, and a $5.500 \mathrm{~L}$ grain tank.

\section{Quality indicators or variables measured}

The data were collected for each plot by monitoring the harvester's activities from the onset of the harvesting operation at 10 minute intervals. The individual designated for this task recorded the activities, separated into four functions, as shown in Table 2. To determine the losses during harvest, 3 circular frames that were covered with an area of $0.33 \mathrm{~m}^{2}$ of sombrite screen were installed (total area of approximately $1.00 \mathrm{~m}^{2}$ ). The frames were released soon after the harvester's platform passed pre-determined points; two frames were located outside of the track of the harvester's wheelsets (left and right) and a third was located between the rear wheelsets (centre) (Fig 8). All of the beans and pods present were collected above and below each rim and stored in a previously identified paper bag.

\section{Statistical analysis}

The results were statistically analysed using the Minitab ${ }^{\circledR} 16$ program, analysing the variability of the mechanised harvest process using statistical process control methods to analyse the control charts for each variable as an analytical tool, where the harvester operational efficiency and the bean losses during harvest were considered to be indicators of quality. The "individual" control charts (four functions) each contain a sequential graph that corresponds to the individual point-topoint values and the established control limits, considering the variation in the results attributed to uncontrolled causes associated with the harvesting process (special causes) and calculated based on the standard deviations of the variables. The means plus or minus approximately three standard deviations were designated as the control limits (Montgomery, 2009). When an observation failed the test for special causes, the data point was highlighted in the control chart, indicating non-random variation in the results that 
should be further investigated. For such cases, the process was considered to be "unstable" or "out of control". If there were no highlighted data in the control chart, the variable was considered to have no special causes of variation, and consequently, the process was considered "stable" or "under statistical control".

\section{Conclusion}

The mechanised harvest operation was unstable, regardless of the plot shape, because the harvest is strongly affected by factors external to the harvesting process. The trapezoidal rectangular plot shape allowed for higher machine production efficiency, whereas the irregular plot shape compromised the harvester's bean unloading function because it did not favour the logistics of transport within the area and; thus, unloading. In terms of soybean losses, there was a difference amongst plot shapes, with greater losses for irregular plot shapes.

\section{References}

Abbasi B (2009) A neural network applied to estimate process capability of non-normal processes. Expert Syst Appl. 36(2):3093-3100.

Araldi PF, Schlosser GF, Frantz UG, Ribas RL, Santos PM (2013) Operational efficiency in mechanical harvesting in irrigated rice crops. Ciênc Rural. 4:445-451.

ASAE (American Society of Agricultural Engineers). ASAE EP 497.6 JUN09: Agricultural machinery management data. In: ASAE Standards 2009: standards engineering practices data. St. Joseph, 2009. p. 350-357.

Bai J (2003) Testing parametric conditional distributions of dynamic models. Rev Econ Stat. 85(3):531-549.

Bai J, Ng S (2005) Tests for skewness, kurtosis, and normality for time series data. J Bus Econ Stat. 23:49-60.

Bakir ST (2012) A Nonparametric Shewhart-type quality control chart for monitoring broad changes in a process distribution. Int J Qual Stat Reliab. 2012:1-10.

Bianco S, Carvalho LB, Bianco MS, Pitelli RA (2012) Accumulated dry mass and macronutrients by Glycine max and Solanum americanum plants'. Planta Daninha. 30:8795.

Carvalho Filho A, Cortez JW, Silva RP, Zago MS (2005) Perdas na colheita mecanizada de soja no triângulo mineiro. Rev Nucleus. 3:57-60.

Carvalho TC, Novembre DLC (2012) Quality of soybeans harvested manually and mechanically with different moisture contents. Semin-Ciênc Agrár. 33:155-166.

Cassia MT, Silva RP, Chioderoli CA, Noronha RHF, Santos EP (2013) Quality of mechanized coffee harvest in circular planting system. Ciênc Rural. 43:28-34.

Chakraborti S (2006) Parameter estimation and design considerations in prospective applications of the $\overline{\mathrm{X}}$ chart. J Appl Stat. 33(4):439-459.

Chioderoli CA, Silva RP, Noronha RHF, Cassia MT, Santos EP (2012) Grain losses and straw distribution in mechanized soybean harvest. Bragantia. 71:112-121.

Costa NP, Mesquita CM, Maurina AC, França-neto JB, Pereira JE, KRzyzanwski FC, Henning AA (2002) Avaliação da qualidade de sementes e grãos de soja provenientes da colheita mecanizada em diferentes regiões do Brasil. Eng Agríc. 22(2): 211-19.

Custodio AAP, Silva RP, Lemos LB, Toledo A, Lima LP (2012) Statistical control applied in mechanized harvest of irrigated coffee. Rev Agr. 1:172-180.

Grisso RD, Kocher MF, Adamchuk VI, Jasa PJ, Schroeder MA (2004) Field efficiency determination using traffic pattern indices. Applied Engineering in Agriculture, v. 20, n. 5, p. 563-572, 2004.distributions. Gestão da Prod. 16(1):121-132.

Holtz V, Reis EF (2013) Perdas na colheita mecanizada de soja: uma análise quantitativa e qualitativa. Rev Ceres. 60(3):347-353.

Léon A, Rubio G, Serna G (2005) Autoregressive conditional volatility skewness and kurtosis. Q Rev Econ Financ. 45:599-618.

Loureiro AM, Silva RP, Cassia MT, Compagnon AM, Voltarelli MA (2014) Effect of sample area on variability in mechanized soybean harvest losses. Rev Eng Agr. 34:74-85.

Molin JP, Milan M, Nesrallah MGT, Castro CN, Gimenez, LM (2006) Utilização de dados georreferenciados na determinação de parâmetros de desempenho em colheita mecanizada. Rev Eng Agr. 26(3):759-767.

Montgomery, DC (2004) Methods and philosophy of statistical process control. In: Montgomery DC (ed) Introduction to statistical quality control, 6rd edn. Wiley, Arizona, pp 179-213.

Montgomery DC (2009) Quality improvement in the modern business environment. In: Montgomery DC (ed) Introduction to statistical quality control, 6rd edn. Wiley, Arizona, pp 3-42.

Mudholkar GS, Natarajan R (2002) The inverse Gaussian models: analogues of symmetry, skewness and kurtosis. Ann I Stat Math. 54(1):138-154.

Noronha RHF, Silva RP, Chioderoli CA, Santos EP, Cassia MT (2011) Statistical control applied to the diurnal and nocturnal mechanized sugarcane harvest. Bragantia. 70:1-8.

Santos NB, Cavalcante DS, Fernandes HC, Gadanha júnior CD (2014) Simulação da eficiência de campo da colheita mecanizada de cana-de-açúcar (Saccharum spp.). Rev Energia na Agric. 29(1): 09-13.

Shinde JH, Katikar RS (2012) Importance of process capability and process performance indices in machine tool. Int J Res Eng App Sci. 2(2):1211-1217.

Silva RP, Cassia MT, Voltarelli MA, Compagnon AM, Furlani CEA (2013) Quality of mechanized bean (Phaseolus vulgaris) harvest in two soil preparation systems. Rev Ciênc Agron. 44:61-69.

Toledo A (2008) Spatial variability and quality process evaluation in peanut sowing. M.Sci. Thesis. Universidade Estadual Paulista, Brasil Universidade Estadual Paulista, Brazil.

Voltarelli MA (2013) Quality of operation mechanized planting of sugarcane in the day and night shift. M. Sci. Thesis. Universidade Estadual Paulista, Brazil.

Zhou C, Tsung F (2010) Likelihood ratio-based distributionfree EWMA control charts. J Qual Technol. 42(2):174196. 